\title{
Marcuse e os limites da sua utopia
}

\author{
Marcuse and the limits of his utopia
}

\section{Sergio Augusto Franco Fernandes}

Doutor em Filosofia pela Universidade de Campinas (Unicamp), professor adjunto do Centro de Artes, Humanidades e Letras (CAHL) da Universidade Federal do Recôncavo da Bahia (UFRB), Cruz das Almas, BA Brasil, e-mail: sergioaffernandes@gmail.com

\section{Resumo}

Marcuse direciona a Freud uma crítica que diz respeito ao estatuto atribuído pela metapsicologia ao "princípio de realidade". Verificaremos, portanto, a consistência de alguns dos seus argumentos e a ideia de um "poder-ser" implícito na sociedade moderna, de cuja ignorância, segundo o próprio Marcuse, teria nascido o pessimismo freudiano. Isso feito, buscaremos nos comentários de Alasdair MacIntyre elementos que colocam em "xeque" a utopia marcuseana, delimitando-a e impossibilitando-a de realizar-se, ao menos do ponto de vista de uma coerência discursiva. Para Maclntyre, a ideia de uma sexualidade não reprimida ou até mesmo autossublimada e liberta não faz sentido até que se responda a seguinte pergunta: $O$ que é que realmente faremos num estado de sexualidade libertada? Para o crítico em questão, a ideia da sexualidade contemporânea estar constrangida pelas limitações de uma cultura sexual genital-monogâmica não faz sentido, até que se possa estabelecer efetivamente algum contraste com algo que seja possível 
realizar e que ainda não foi realizado. Entretanto, a crítica de qualquer utopia não deveria jamais desembocar na crítica do espírito utópico.

Palavras-chave: Freud. Marcuse. Princípio de progresso. Princípio de realidade. Utopia.

\section{Abstract}

Marcuse directs a criticism to Freud that relates to the status assigned by the "reality principle" metapsychology. So we will check the consistency of some of his arguments and the idea of a "can-be" implicit in modern society, in whose ignorance, even according to Marcuse, Freudian pessimism was born. After this, we will seek the comments of Alasdair Maclntyre elements that pose a "sheikh" utopia Marcuse, delimiting it and preventing it from place, at least from the standpoint of a coherent discourse.

Keywords: Freud. Marcuse. Principle of progress. Reality principle. Utopia.

Herbert Marcuse cogitou a existência de um panorama utópico em que a afirmação da liberdade se daria a partir dos contrasensos produzidos pelas formas socioculturais do capitalismo tardio. A construção e a articulação desse panorama somente pôde se estabelecer graças ao seu conhecimento da metapsicologia freudiana, convocada e utilizada para servir de fundamento antropológico para sua teoria social. Apresentaremos, então, de forma sucinta, a crítica que Marcuse endereça a Freud, que diz respeito ao estatuto atribuído pela metapsicologia ao "princípio de realidade", com o intuito de verificarmos a consistência de alguns dos seus argumentos e a ideia de um "poder-ser" implícito na sociedade moderna, de cuja ignorância, segundo o próprio Marcuse, teria nascido o pessimismo freudiano. Isso feito, buscaremos nos comentários de Alasdair MacIntyre elementos que colocam em "xeque" a utopia marcuseana, delimitando-a e impossibilitando-a de realizar-se, ao menos do ponto de vista de uma coerência discursiva.

Em Eros e civilização, publicado em 1955 (MARCUSE, 1999), deparamo-nos com o desenvolvimento de um tema considerado por muitos como um dos tópicos mais importantes do pensamento de Freud, qual seja, a teoria que diz que a civilização se baseia na repressão permanente 
das pulsões do homem, obstaculizando, dessa maneira, a conquista da felicidade. Isso quer dizer que, pela própria natureza das pulsões, a felicidade se mostra virtualmente impossível. Vale lembrar que, para Freud, a felicidade não se apresenta como um valor da cultura.

Marcuse, interpretando Freud, diz que a felicidade estaria subordinada: I - a um trabalho que ocupa toda a jornada do indivíduo; II - à disciplina da reprodução monogâmica; III - ao sistema constituído das leis e da ordem. Isso quer dizer que o sacrifício metódico da libido e seu desvio imposto para atividades e expressões socialmente úteis, pela via da sublimação das pulsões, constituiriam a cultura. Quanto à sublimação, essa seria uma das vias que a civilização impõe ao sujeito para assegurar o controle das pulsões.

Dito de forma bem simplória, o sujeito deslocaria a sua energia pulsional dos alvos sexuais para a produção de atividades socialmente aceitas. O sujeito encontraria, na criação artística, por exemplo, uma maneira própria e subjetiva de satisfação ao transformar os seus "restos pulsionais", auxiliando, assim, na redução dos poderes repressivos e inibidores da cultura, modificando-a. Entretanto, a sublimação não deve ser considerada, em absoluto, exclusividade do mundo das artes; o ato de sublimar possui também a qualidade de fortalecer os laços sociais entre os homens, solicitando mudanças e desenvolvendo grandes criações culturais.

Para Marcuse, Eros também possui uma face absolutamente sinistra, principalmente quando se encontra a serviço da pobreza psicológica dos grupos sociais. Nessa perspectiva, a "cultura" ou "civilização" termina por impor constrições sociais e biológicas ao indivíduo, sendo essas constrições a condição preliminar do progresso. Sabemos que, para Freud, a história do homem é a história de sua repressão. Isso quer dizer que as próprias forças que tornam a sociedade capaz de arrefecer a luta pela existência acabam por servir para recalcar nos indivíduos a necessidade de uma libertação:

a democracia de massa fornece os apetrechos políticos para efetuar-se essa introjeção do "princípio de realidade"; não só permite às pessoas (até um certo ponto) escolherem seus próprios senhores e amos, e 
participarem (até um certo ponto) no Governo que as governa, como também permite aos senhores e amos desaparecerem por trás do véu tecnológico do aparelho produtivo e destrutivo que eles controlam, e esconderem o preço humano (e material) dos benefícios e conforto concedidos àqueles que colaboram. O povo, eficientemente manipulado e organizado, é livre; a ignorância e a impotência, a heteronomia introjetada, é o preço de sua liberdade (MARCUSE, 1999, p. 14).

Marcuse faz referência a um "inferno" então concentrado em certos lugares distantes, onde foram constatados bolsões de pobreza e muita miséria, em diversas sociedades em crescimento. Havendo a possibilidade de eliminação desses "bolsões" de pobreza, questiona, então, qual seria o preço a se pagar por isso. Nosso frankfurteano hesita em empregar a palavra liberdade, haja vista que sempre foi em nome da "liberdade" que os crimes contra a humanidade foram cometidos; seriam situações que se repetem na história, ou seja, pobreza e exploração como produtos da liberdade econômica. Ironicamente, ele fala de povos que outrora foram libertados pelos seus amos e senhores pela submissão à força, logo se convertendo em "servos voluntários", que acabavam por colaborar na reprodução de uma sociedade que, com o tempo, tornou a servidão cada vez mais "compensadora e agradável".

Para o referido autor, essa união entre liberdade e servidão seria vista, ao menos na sua época, como algo natural, como um "veículo" do progresso. Em contraste com essa confusão entre liberdade e agressão, produção e destruição, a imagem da liberdade humana estaria deslocada, isto é, convertida num projeto da subversão dessa espécie de progresso. Portanto, a partir do que foi dito, a tese de Eros e civilização poderia se resumir ao seguinte: o homem somente poderia evitar a fatalidade de um estado de guerra mediante a instituição de um novo ponto de partida, pelo qual fosse possível a reconstrução do sistema produtivo sem um certo "ascetismo do mundo interior", elemento este que forneceria a base mental para a dominação e para a exploração. É proposta, então, a ideia de um novo "princípio de realidade", baseada no pressuposto de que as precondições materiais (técnicas) para o seu desenvolvimento já estariam estabelecidas ou poderiam 
ser estabelecidas nas sociedades industriais mais avançadas do nosso tempo.

Tentemos esclarecer. A interpretação do aparelho psíquico, conforme os princípios de prazer e de realidade, mostra-se fundamental para a teoria freudiana, visto que permanece a mesma, embora com todas as modificações a partir da concepção dualista das pulsões. A transformação do princípio de prazer em princípio de realidade corresponde, em parte, à distinção entre processos inconscientes e processos conscientes. Seria como se o indivíduo existisse em duas dimensões distintas marcadas por diferentes processos e princípios psíquicos. Haveria, entre essas duas dimensões, uma distinção tanto da ordem histórico-genética quanto estrutural, em que o inconsciente, governado pelo princípio de prazer, compreenderia os mais arcaicos processos primários, restos de um momento de desenvolvimento em que eles foram as únicas espécies de processos psíquicos. Buscando, a todo momento, a obtenção de prazer, a atividade psíquica acabaria por retrair-se, evitando qualquer operação que pudesse originar sensações de desprazer ou dor.

Contudo, acontece que o princípio de prazer, irrestrito, entra em conflito com o mundo natural e humano, fazendo com que o indivíduo alcance uma compreensão, embora traumática, de que uma gratificação total e sem sofrimento, de suas necessidades, mostra-se impossível. Após essa experiência de decepção, um novo princípio de funcionamento psíquico ganharia ascendência e notoriedade; assim, o princípio de realidade superaria o princípio de prazer, na medida em que o homem aprenderia a renunciar ao prazer efêmero, incerto e destrutivo, substituindo-o pelo seu adiamento restrito, porém garantido. Seria, então, em função desse ganho duradouro, por meio da renúncia e da restrição, que o princípio de realidade "salvaguardaria" mais que "destronaria" o princípio de prazer, modificando-o mais do que o negando:

com o estabelecimento do princípio de realidade, o ser humano que, sob o princípio de prazer, dificilmente pouco mais seria do que um feixe de impulsos animais, converte-se num ego organizado. Esforça-se por obter "o que é útil" e o que pode ser obtido sem prejuízo para si próprio e para o seu meio vital. Sob o princípio de realidade, o ser humano 
desenvolve a função da razão: aprende a "examinar" a realidade, a distinguir entre bom e mau, verdadeiro e falso, útil e prejudicial. O homem adquire as faculdades de atenção, memória e discernimento. Torna-se um sujeito consciente, pensante, equipado para uma racionalidade que lhe é imposta de fora (MARCUSE, 1999, p. 35).

Como podemos notar, os dois princípios coexistem e atuam concomitantemente de maneira incômoda e quase sempre conflituosa. Ressaltamos que, para Freud, desde o texto Formulaciones sobre los dos principios del acaecer psíquico, de 1911 (FREUD, 1996a), o prazer, como princípio que rege o nosso funcionamento psíquico, trabalha como uma tendência à qual o psiquismo adere, sendo que somente na aparência é que o princípio de realidade o suprime.

Retornemos ao texto de Marcuse, mais especificamente à questão que diz respeito à ideia de um novo "princípio de realidade". Para o referido autor, de forma implícita, na tradução das capacidades técnicas em realidade significava revolução, porém, a própria eficácia da introjeção democrática havia suprimido o sujeito histórico, o agente da revolução. Se assim fosse, as pessoas livres não necessitariam de libertação e as oprimidas não seriam suficientemente fortes para libertarem-se. Diz o pensador:

essas condições redefinem o conceito de Utopia: a libertação é a mais realista, a mais concreta de todas as possibilidades históricas e, ao mesmo tempo, a mais racionalmente, mais eficazmente reprimida - a possibilidade mais abstrata e remota. Nenhuma filosofia, nenhuma teoria pode desfazer a introjeção democrática dos senhores em seus súditos (MARCUSE, 1999, p. 16).

Isso quer dizer que o conflito entre senhores e escravos, numa sociedade em desenvolvimento, seria eficientemente contido ao ocorrer o seguinte: quando a produtividade atingisse um nível em que as massas participassem de seus benefícios e quando a oposição fosse eficaz e democraticamente "contida". As revoluções do passado, na perspectiva marcuseana, acarretaram um desenvolvimento bastante amplo e mais racional das forças produtivas nas sociedades mais avançadas, 
porém, revolução, nesse sentido, significaria a inversão dessa tendência, a saber: eliminação do superdesenvolvimento e de sua racionalidade repressiva.

Vamos, agora, abordar uma questão fundamental, que diz respeito às colocações elaboradas em Eros e civilização (MARCUSE, 1999) e, talvez, melhor respondidas em A noção de progresso à luz da psicanálise (MARCUSE, 2004). Sabe-se que o conceito de progresso é definido, sobretudo, do ponto de vista quantitativo, sendo o resultado desse progresso a riqueza social crescente. Constatamos que, com o desenvolvimento da civilização, as necessidades humanas e os meios de satisfazê-las têm aumentado, deixando, pois, uma questão em aberto: até que ponto esse progresso contribui, de forma equitativa, para o aperfeiçoamento do homem, para uma existência mais livre e mais feliz? Marcuse denomina esse conceito de progresso de técnico, que se opõe a outro conceito, o de progresso qualitativo, elaborado pela filosofia idealista, talvez de maneira decisiva por Hegel. Esse progresso qualitativo consistiria na realização da liberdade humana, na realização da moralidade: "O resultado do progresso aqui consiste na humanização progressiva dos homens, no desaparecimento da escravidão, do arbítrio, da opressão e do sofrimento" (MARCUSE, 2004, p. 100). Podemos, então, chamar esse conceito qualitativo progresso de humanitário.

Marcuse aponta para a existência de uma conexão íntima entre os dois conceitos de progresso aos quais ele faz referência: o progresso técnico parece ser a pré-condição de todo progresso humanitário. Por um lado, a ascensão da humanidade ocorre a partir da escravidão e da miséria a uma liberdade cada vez maior, um alto grau de domínio da natureza que levaria à riqueza social; por outro lado, não é de modo algum evidente que o progresso técnico leve, automaticamente, ao progresso humanitário. É necessário, pois, saber de que maneira a riqueza social é repartida e a serviço de quem os crescentes conhecimentos e capacidades dos seres humanos são empregados. Em resumo, o progresso técnico, pré-condição da liberdade, não significaria, de maneira nenhuma, a realização de uma liberdade maior. Eis a questão: se o mais alto valor do progresso técnico consiste na produtividade, questionemos, então: produtividade para quê? 
Invariavelmente, a resposta é a seguinte: para satisfazer as necessidades. Realmente, a produtividade serve para satisfazer as necessidades, já que o fim último desta consiste na produção de valores de uso que devem ser revertidos em favor dos seres humanos. Contudo, diz o nosso frankfurteano:

mas quando o conceito de necessidade engloba tanto alimentação, roupa, moradia quanto bombas, máquinas caça-níqueis e a destruição de produtos invendáveis, então podemos afirmar como certo que o conceito é tão desonesto quanto inútil para determinar o que seria uma produtividade legítima, e temos o direito de deixar em aberto a pergunta: produtividade para quê? Parece que a produtividade é cada vez mais um fim em si mesmo, e a pergunta sobre a sua utilização não só permanece em aberto, como é cada vez mais recalcada (MARCUSE, 2004, p. 102).

Sendo assim, produtividade e progresso mostram-se inseparáveis, resultando daí que a vida deve ser sentida e vivida como trabalho, em que o próprio trabalho deveria tornar-se o conteúdo da vida, sendo concebido como socialmente necessário e útil, não sendo, em absoluto, do ponto de vista da individualidade, satisfatório e necessário. A satisfação, então, nunca deve ser considerada aquilo que pode vir a constituir o conteúdo e o espaço da liberdade. De acordo com Marcuse, a liberdade, definida como fim em si mesma e rigorosamente separada da satisfação, acaba por tornar-se liberdade infeliz.

Percebe-se que o conceito de progresso por ele delineado, em virtude do próprio progresso, apresenta-se carregado de negatividade e de transcendência pela transcendência, sendo, dessa maneira, hostil à felicidade e à paz. Aproximando-se de Freud, Marcuse formula a seguinte questão: “[...] o progresso está necessariamente fundado na infelicidade e precisa necessariamente ficar ligado à infelicidade, à insatisfação?" (MARCUSE, 2004, p. 105).

Se a alegria, a satisfação e a paz, por exemplo, podem trazer felicidade ao indivíduo, entretanto, não necessariamente são úteis ao progresso, já que a guerra, no sentido de luta pela vida, pode ser considerada a "mãe" de todas as invenções progressistas na medida em que tais invenções contribuem para o melhoramento e a satisfação das 
necessidades humanas. De acordo com Marcuse, a frustração e o sofrimento foram o estímulo de todo trabalho da civilização até os dias de hoje. Questiona, todavia, o porquê da subjugação do princípio de prazer pelo princípio de realidade se mostrar indispensável ao desenvolvimento da civilização; e em que consistiria, propriamente, o princípio de realidade como "princípio de progresso". Ele mesmo responde: "Segundo a versão tardia da teoria freudiana das pulsões, sobre a qual me apoio aqui, o organismo com suas duas pulsões fundamentais, Eros e pulsão de morte, não é socializável enquanto essas pulsões não forem limitadas" (MARCUSE, 2004, p. 107).

Para Freud, como sabemos, o princípio de realidade nada mais é que o princípio da renúncia produtiva, que modifica as pulsões, as renúncias, as substituições, as sublimações que a sociedade deve impor aos indivíduos para transformá-los, de portadores do princípio de prazer em instrumentos de trabalho socialmente úteis. Seria, pois, nesse sentido que Marcuse fez valer uma equivalência entre o princípio de realidade e o que ele denominou princípio de progresso, haja vista que somente por meio do princípio de realidade repressivo a energia pulsional para o trabalho desprazeroso poderia ser liberada. O aumento da quantidade de energia acumulada na renúncia da satisfação seria seguido de um aumento da produtividade, a qual não levaria à satisfação individual. Marcuse fala aí de um "círculo vicioso do progresso", em que a crescente produtividade do trabalho social continuaria ligada a uma crescente repressão que, por sua vez, contribuiria para o aumento da produtividade. Vamos ver a sua formulação a respeito da autorrenúncia presente no "princípio de progresso":

as inclinações dos homens devem ser continuamente sacrificadas à razão, a felicidade à liberdade transcendental para que os homens, por meio da promessa da felicidade, sejam mantidos no trabalho alienado, permaneçam produtivos, se proíbam fruir plenamente de sua produtividade e perpetuem assim a própria produtividade (MARCUSE, 2004, p. 112).

Consideremos, pois, a hipótese freudiana acerca da origem da história humana, encontrada em Tótem y tabú (FREUD, 1996b), 
abstraindo-se seu possível conteúdo empírico, para percebermos uma imagem da "dialética da dominação", sua gênese, sua transformação e desenvolvimento com o progresso da civilização. Com a interiorização da dominação paterna, que marca a origem da moralidade e da consciência moral, inicia-se, pois, a cultura e a civilização, sendo a horda primitiva um correlato da primeira sociedade humana.

Essa dinâmica da dominação, iniciada com o estabelecimento do despotismo, levaria à revolução e, depois da primeira tentativa de libertação, terminaria por restabelecer o pai numa forma mais interiorizada e mais universal, ou seja, numa forma mais racional: “Essa repetição psicológica da dinâmica da dominação na civilização se exprime igualmente na história mundial, na dinâmica das revoluções passadas, que sempre retorna" (MARCUSE, 2004, p. 114). A modificação repressiva das pulsões, não sendo nem natural nem historicamente inalterável, apresenta um limite bem determinado, que aparece somente depois que a repressão das pulsões e o progresso cumprem sua função histórica, qual seja, superar a impotência humana e a escassez de bens quando a sociedade livre tiver se tornado uma possibilidade real para todos. Percebe-se, aí, uma intervenção na teoria freudiana:

o princípio de realidade repressivo torna-se supérfluo à medida que a civilização se aproxima de um estágio em que a eliminação de um modo de vida que força a repressão das pulsões se tornou uma possibilidade histórica realizável. As conquistas do progresso repressivo anunciam a superação do próprio princípio do progresso repressivo. Pode-se prever uma situação em que não exista produtividade, simultaneamente resultado e condição da renúncia, em que não exista trabalho alienado [...]. O tempo gasto no trabalho alienado não seria mais o tempo da vida, nem o tempo livre dado ao indivíduo para satisfazer as próprias necessidades seria um mero resto de tempo; ao contrário, o tempo de trabalho alienado seria não apenas reduzido ao mínimo, mas desapareceria completamente, e o tempo da vida seria o tempo livre (MARCUSE, 2004, p. 116).

Seguindo esse raciocínio, a hierarquia de valores de um princípio de progresso não repressivo poderia ser determinada quase, 
ponto por ponto, em oposição ao princípio de progresso repressivo. Nesse sentido, a experiência essencial da vida já não mais seria a luta pela existência e, sim, a sua fruição, na medida em que o trabalho alienado fosse se transformando num livre jogo de forças e capacidades humanas. Se o trabalho se transformasse em livre jogo das capacidades humanas, o sofrimento deixaria de ser necessário para coagir os homens a trabalhar, visto que, por si mesmos e tão somente por ser a satisfação de suas próprias necessidades, os homens trabalhariam para construir um mundo melhor, onde a existência se satisfaria a si mesma.

Nosso pensador de Frankfurt expõe, portanto, uma utopia na qual se afirma que a sociedade industrial moderna poderia, muito em breve, alcançar um estágio em que o princípio de repressão, que ainda hoje guia seu desenvolvimento, se revelaria obsoleto. Diz ele o seguinte: “Talvez seja hoje menos irresponsável pintar uma utopia fundamentada que difamar como utopia condições e possibilidades que já há muito se tornaram possibilidades realizáveis" (MARCUSE, 2004, p. 122).

Retomemos, de forma breve, o conteúdo da sua crítica ao pensamento de Freud. Como vimos, ele diz respeito ao estatuto atribuído pela metapsicologia ao "princípio de realidade". Diferentemente de alguns marxistas, ele não compartilha o preconceito em relação à psicanálise. Muito pelo contrário, a psicanálise lhe parece com uma psicologia social e histórica que refaz, em seu nível, a arqueologia da repressão e da alienação, complementando, assim, o movimento da teoria crítica. A estrutura do aparelho psíquico e o destino do indivíduo foram definidos como o resultado de um longo processo que é, indissoluvelmente, biológico e social. A história natural da vida e a história social das instituições foram os dois fios com os quais Freud alinhavou a oposição básica entre prazer e realidade, que implica todo o edifício do aparelho psíquico. No nível da origem da espécie, o trauma acontece na horda primitiva, quando o pai "primordial" monopoliza o poder e o prazer, impondo a renúncia por parte dos filhos; já no nível do indivíduo, a experiência repete-se sempre no começo da infância, quando os adultos impõem à criança a lei da realidade: 
mas tanto no nível genérico como no individual, a submissão é continuamente reproduzida. Ao domínio do pai primordial segue-se, após a primeira rebelião, o domínio dos filhos, e o clã fraternal desenvolve-se para dar origem a um domínio social e político institucional. O princípio de realidade materializa-se em um sistema de instituições. E o indivíduo, evoluindo dentro de tal sistema, aprende que os requisitos do princípio de realidade são os da lei e da ordem, e transmite-os à geração seguinte (MARCUSE, 1999, p. 36).

No que diz respeito a essa genealogia biossocial do aparelho psíquico, o que interessou a Marcuse foram suas consequências para a análise da civilização contemporânea. A ótica instaurada por Freud, como antes dela a de Nietzsche, apresenta o processo civilizatório como sendo um admirável processo de repressão e destruição. Contudo, é compreensível que Marcuse tenha lido a narrativa freudiana de acordo com o ritmo dialético da alienação, desencadeada pela contradição entre os princípios de prazer e de realidade. Foi, pois, esse alinhamento dialético da contradição que o obrigou a colocar em novos termos os dois princípios, tornando possível a reconciliação entre esses dois adversários. Para ele, o trabalho pacificador da dialética e a ideia de uma civilização não repressiva que esse trabalho promove, não ferem a vocação mais profunda do pensamento de Freud. Quanto a isso, diz Bento Prado Jr. (2005, p. 54):

tudo se passa, ao contrário, como se apenas houvesse faltado a Freud um pequeno impulso para dar por si mesmo esse passo final, a que o convidava todo o seu itinerário anterior, ou seja, para formular a hipótese de um "novo" princípio de realidade. Um princípio de realidade novo, já que tornado possível pelo desenvolvimento social criado à custa do império do princípio de rendimento, da repressão e da mais-repressão.

De acordo com Bento Prado Jr., como a teoria das pulsões se mostra essencialmente histórica, não haveria nenhuma impossibilidade lógica para esse desdobramento teórico. Entretanto, para MacIntyre, o pensamento de Marcuse apresenta uma série de problemas, o que não vem ao caso elencá-los nesse momento, ficando essa tarefa talvez para uma próxima empreitada. Porém, vale ressaltar, ao 
menos, uma das suas objeções, que diz respeito diretamente ao que acabamos de expor. Para MacIntyre, a ideia de uma sexualidade não reprimida ou até mesmo autossublimada e liberta não faz sentido até que se responda a seguinte pergunta: “O que é que realmente faremos num estado de sexualidade libertada?" (MACINTYRE, 1993, p. 54). Para nosso crítico, a ideia de a sexualidade contemporânea estar constrangida pelas limitações de uma cultura sexual genital-monogâmica não faz sentido, até que se possa estabelecer efetivamente algum contraste com algo que seja possível realizar e que ainda não foi realizado:

assim, a falha de Marcuse neste ponto é fatal para toda a sua tese. E, novamente, sua falha se relaciona com a falta de interesse pelos fatos empíricos. Ele revisa Freud em função da sua própria teoria; mas evidentemente considera líquido e certo que a versão freudiana da sexualidade não é fundamentalmente defectiva e, assim, não faz nenhuma tentativa de investigar por si mesmo os fatos a respeito da sexualidade. Não admira que a sua manipulação de teorias antagônicas e incompatíveis chegue às raias do escandaloso (MACINTYRE, 1993, p. 55).

Apesar das contundentes críticas desse reconhecido e competente epistemólogo, Marcuse, ao menos, teve a coragem de defender uma tese utópica, em meio a um pessimismo e um conformismo que predominaram nos anos 50. E, para finalizar, busquemos nas palavras de Luiz Roberto Monzani uma tentativa de arrefecer as impetuosas críticas de MacIntyre dirigidas a Marcuse:

antes de se criticar o discurso utópico, em virtude da impossibilidade de sua realização; antes mesmo de nos engajarmos numa apologia estéril desse mesmo discurso, devemos, sobretudo, procurar questionar nesses discursos aquilo que eles podem nos oferecer. E eles nos ensinam muito sobre nossa natureza, sobre nossos desejos e aspirações e seus limites e contradições (MONZANI, 2008, p. 239).

Aproveitemos, portanto, o fascínio exercido pela utopia marcuseana, na medida em que ela, ao se instalar no nosso imaginário, fisga o nosso desejo de justiça e de realização de muitas coisas a que 
aspiramos, servindo também para mostrar o poder de recuo e de crítica que possuímos. Sendo assim, levando em conta as palavras de Monzani, a crítica de qualquer utopia não deveria jamais desembocar na crítica do espírito utópico.

\section{Referências}

FREUD, S. Formulaciones sobre los dos principios del acaecer psíquico (1911). In: FREUD, S. Obras completas. Traducción de J. L. Etcheverry. Buenos Aires: Amorrortu, 1996a. v. XII.

FREUD, S. Tótem y tabú (1912-1913). In: FREUD, S. Obras Completas. Traducción de J. L. Etcheverry. Buenos Aires: Amorrortu, 1996b. v. XIII.

MACINTYRE, A. As idéias de Marcuse. Tradução de Jamir Martins. São Paulo: Cultrix, 1993.

MARCUSE, H. A noção de progresso à luz da psicanálise. In: MARCUSE, H. Cultura e psicanálise. Tradução de Wolfgang Leo Maar, Robespierre de Oliveira e Isabel Loureiro. Rio de Janeiro: Paz e Terra, 2004. p. 112-138.

MARCUSE, H. Eros e civilização. Uma interpretação filosófica do pensamento de Freud. Tradução de Álvaro Cabral. Rio de Janeiro: Guanabara Koogan, 1999. MONZANI, L. R. et al. Os limites da utopia. In: AIRES, S.; RIBEIRO, C. (Org.). Ensaios de filosofia e psicanálise. São Paulo: Mercado de Letras, 2008. p. 226-240.

PRADO JR., B. Entre o alvo e o objeto do desejo: Marcuse, crítico de Freud. In: FULGENCIO, L.; SIMANKE, R. (Org.). Freud na filosofia brasileira. São Paulo: Escuta, 2005. p. 51-69.

Recebido: $18 / 05 / 2011$

Received: 05/18/2011

Aprovado: 20/07/2011

Approved: 07/20/2011 